\title{
La triste historia de amor del hombre-perro y la mujer con maleta
}

Antonio Hernández Centeno

\section{(2) OpenEdition}

1 Journals

Edición electrónica

URL: https://journals.openedition.org/cher/1142

DOI: $10.4000 /$ cher. 1142

ISSN: 2803-5992

\section{Editor}

Presses universitaires de Strasbourg

\section{Edición impresa}

Fecha de publicación: 11 julio 2019

Paginación: 179-181

ISBN: 979-10-344-0046-1

ISSN: 1968-035X

Referencia electrónica

Antonio Hernández Centeno, «La triste historia de amor del hombre-perro y la mujer con maleta», reCHERches [En línea], 22 | 2019, Publicado el 05 octubre 2021, consultado el 17 noviembre 2021. URL: http://journals.openedition.org/cher/1142 ; DOI: https://doi.org/10.4000/cher.1142 


\title{
La triste historia de amor del hombre-perro y la mujer con maleta
}

\author{
Antonio Hernández Centeno
}

A

Humo de trenes. Humo de aviones. Humo de coches. Olor a gasolina, a metal, a ruedas quemadas. Tierra seca, árida por donde las personas arrastran sus pies, sus almas que avanzan perdidas entre el polvo y el humo. Se sientan, descansan, se vuelven a levantar, caminan, esperan... esperan. Una mujer de mirada huidiza arrastra su maleta buscando un refugio, mirando el polvo de la tierra seca, esperando a que un avión, un tren o un simple autobús la transporte a algún otro lugar.

Por megafonía una voz de mujer cansada, falsamente amable y monótona repite sin orden, sin ritmo, sin nada... consejos de comportamiento.

- Por su propia seguridad les aconsejamos que tengan en todo momento controlados sus equipajes y pertenencias.

- Les rogamos que utilicen las zonas señalizadas para fumar.

- Les aconsejamos que tengan silenciados sus teléfonos móviles y los utilicen en las plataformas señalizadas para dicho uso.

- Les pedimos que mantengan limpia la zona de transito. Hay áreas destinadas al descanso, al rezo y al aseo personal.

- Por su propia seguridad les rogamos que tengan siempre disponibles sus tarjetas de identificación.

B

Un hombre sudoroso, nervioso, mojado llega a la zona de transito. Un fuerte olor le sorprende y comienza a olfatear como si fuera un perro de caza que acaba de localizar a su presa. El hombre ladra con fuerza, parece más un lobo que un perro... el sudor impregna su cuerpo... comienza a correr entre las personas, rastreando... ubicando a su presa. La mujer de la maleta, al oír el primer ladrido, se incomoda, mira hacia atrás y comienza a huir. Se crea una curiosa y violenta persecución. Nadie se involucra en lo que ocurre. Nadie interviene. Nadie hace nada. 
Hombre-Perro.- Guau... Guau... ¡No huyas! Guau... Guau... ¡Te alcanzaré!

La MUjer de la Maleta.- ¡Vete!... ¡Ayúdenme!... ¡No te acerques!

Hombre-Perro.- Quiero tu perdón... podemos volver...

La mujer de la Maleta.- Olvídame... ¡Por favor... que alguien me ayude!

Hombre-Perro.- Vengo a por ti...

LA MUJer DE la Maleta.- Tenía que haber desaparecido.

Hombre-Perro.- Pero no lo has hecho... has dejado tu rastro para que te encuentre y me arrastre hasta ti...

LA MUJer de la Maleta.- ¡A Apártate! ¡No me toques!

Hombre-Perro.- ¡Mírame, mírame! ¡Solo un segundo....!

El hombre-perro la rodea y comienza a olerla, husmeando por todo el cuerpo de la mujer que cada vez se tensa más y más e intenta apartarlo, pero el hombreperro es más fuerte y sabe cómo imponerse sobre ella.

La mujer de la Maleta.- ¡Deja de olerme! ¡Aléjate de mí!

La mujer de megafonía no deja de dar consejos mientras el hombre-perro arrincona a la mujer contra un muro.

C

Hombre-Perro.- - Te voy a contar una historia... una historia que ha viajado a través del tiempo.

La MUjer de la Maleta. - No me interesan tus malditos cuentos ...

Hombre-Perro. - ¡Vas a escuchar como hacías cada noche antes de dormir...!

LA MUjer de la Maleta.- ¡Me repugna tu voz!

El hombre-perro la tumba con violencia en la tierra seca. Se eleva sobre ella. Con tranquilidad saca su verga del pantalón y mientras le cuenta la historia mea sobre la mujer y sobre la tierra que la rodea con violencia.

Hombre-Perro.- Esta es la historia de Zeus y la Bella Dannae, hija de Acrisio, rey de Argos. Todos los hombres del Peloponeso estaban enamorados de la serena belleza de Dannae, pero su padre no le permitía que se casará con ninguno; porque el oráculo había anunciado que el primer hijo que engendrara daría muerte al viejo Rey. Acrisio, para evitar que se cumpliera la predicción, apartó a su virgen hija del trato con todos los hombres y la encerró en una torre de bronce. El monarca lloró delante de todos la falsa muerte de su hija. Pero Zeus, padre de los dioses y los hombres, conocía la verdad y se convirtió en una nube dorada y resplandeciente que se acercó hasta la ventana de la torre de bronce, donde vivía cautiva la bella Dannae, y descargó toda su lluvia sobre ella, para así poder concebir ese hijo. LA MUJer de la Maleta.- Jamás tendremos uno... jamás... 
Hombre-Perro empieza a amasar el barro que ha creado con su propio orín, construye algo con el barro.

Hombre-Perro.- A partir de ahora esta será tu cárcel dorada... este lugar ya nos pertenece... aquí nacerá... en este trozo de tierra...

La mujer de la Maleta.- Baldío... estéril... como tú...

Hombre-Perro.- Sabe a sal, a mar, a vida. ¡Saboréalo!

El Hombre-Perro la fuerza a tragar el barro formado con la tierra seca y su orín.

Hombre-Perro.- Soy capaz de crear con lo que hay dentro de mí. Así que voy a edificar nuestra casa, donde volveremos a ser felices ¡No la rechaces!

La mujer con maleta escupe el barro a la cara del Hombre-perro y vomita cada una de las frases con rabia y miedo. Casi arrinconando al hombre-perro que se refugia en el rincón.

La mujer de la Maleta.- Anomalías en la producción de espermatozoides: que se pueden deber a un fallo testicular primario o daño testicular, ya sea anatómico por infección (paperas) o por toxinas, tales como: tabaco, calor, radiación, metales pesados, pesticidas, alcohol o drogas. Desgraciadamente la mayoría de la infertilidad masculina es idiopática, es decir, se sabe que algo falla pero no se sabe exactamente qué es, lo cual dificulta la imposición del tratamiento. La gran mayoría de las ocasiones la infertilidad desemboca en claros casos de impotencia; que se caracterizan por la incapacidad de mantener una erección el tiempo suficiente como para poder realizar el coito y luego eyacular.

E

El hombre-perro se revuelve contra ella. Localiza un palo en el suelo y con violencia se lo introduce por la vagina. A la misma vez que intenta besarla. Ella grita y el grito va perdiendo fuerza como la vida se escapa por su boca.

Hombre-Perro.- Te debo un beso, de los siete que siempre suelo regalarte al despertar. Uno en la cara, otro en el cuello, otro en la espalda, bueno en la espalda suelo darte dos para luego ir bajando, repartiendo por tus glúteos hasta llegar así a tus pies... Es allí donde suelo alojar el último, en algún borde de tu pie derecho... Pero te moviste y empezaste a hablar... hablar con mucha convicción, la que tú no sueles tener por las mañanas y no pude darte ese último beso en algún dedo de tu pie derecho. Mientras hacías la maleta no parabas de hablar... cada vez con menos convicción y más volumen... Ahora sigo suspendido en ese séptimo beso que no te di, suspendido de él, necesitado de él... Precisando que mi boca vuelva a recorrer como cada mañana ese reverso de ti misma que cada día vuelve a la vida entre las sábanas de mi cama... Me gustaría volver a ese beso no dado porque es algo que voy a dejar pendiente, algo que te debo por los siglos de los siglos de los siglos de los siglos... Algo que solo tú sabrás que te debo... un beso... mi beso. 
El hombre-perro saca el palo baldío de dentro de ella. La mujer con maleta se desploma... Él se acurruca a su lado como si fuera un perro y se adormece acunado por la voz de megafonía que no deja de dar consejos. 